\title{
Study of Brainstem Evoked Response Audiometry to Assess Hearing Loss in High Risk Children Below 5 Years
}

\author{
Suganshi Garg1 and Borlingegowda Viswanatha ${ }^{2 *}$ \\ ${ }^{1}$ Senior Resident, ENT Department, Bangalore Medical College and Research Institute, India \\ ${ }^{2}$ Professor \& Head of ENT Department, Bangalore Medical College and Research Institute, India
}

*Corresponding author: Viswanatha B, Professor Department of Otorhinolaryngology, Bangalore Medical College and Research Institute, India

\begin{abstract}
Early detection of hearing loss and intervention is very important for the development of normal speech and language. A prospective study of brainstem evoked response audiometry to access hearing loss in high risk children below 5 years of age, to find out the incidence of hearing loss in children from high risk category and to determine the threshold of hearing by brainstem evoked response audiometry in high risk children by observing wave ' $V$ ' at the minimum intensity of click stimulus. 100 children having one or more high-risk factors for hearing loss (up to 5 years of age) according to the inclusion criteria had been selected for the study from the outpatient department. This study showed that BERA was found to be a useful, accurate tool to detect the type of hearing loss and the site of defect in auditory transmission of sound. This aids in planning the mode of intervention for early rehabilitation for speech and language development.
\end{abstract}

Keywords: Brainstem evoked response audiometry; hearing loss; high risk children

\section{Introduction}

Early detection of hearing loss and intervention is very important for the development of normal speech and language. In India, 63 million people (6.3\%) suffer from significant auditory loss. Four in every 1000 children suffer from severe to profound hearing loss. With over 100,000 babies that are born with hearing deficiency every year approximately $50 \%$ of all cases of congenital hearing loss are attributable to environmental factors such as congenital hyperbilirubinemia, ototoxic medication exposure, neonatal hypoxia, viral infections, and meningitis. The other $50 \%$ of cases are thought to be inherited, i.e., of genetic causes. Of these hereditary cases approximately $30 \%$ are classified as syndromic [1]. In a developing country like India newborn hearing screening is yet to be implemented. Joint committee on infant hearing recommends BERA (brainstem evoked response audiometry) technology as the only appropriate screening technique for use in the NICU (neonatal intensive care unit) (Figures 1-3). For infants who do not pass BERA testing in the NICU referral should be made directly to an audiologist for rescreening and when indicated comprehensive evaluation including diagnostic BERA should be done [2]. BERA is a far-field recording of the synchronized response of numerous neurons in the auditory pathway within the brainstem. BERA was first described by Sohmer and Feinmesser in 1967. It reflects neural activity generated at the level of the brainstem because of which it is not strongly affected by attention, sleep, or sedation [3]. 


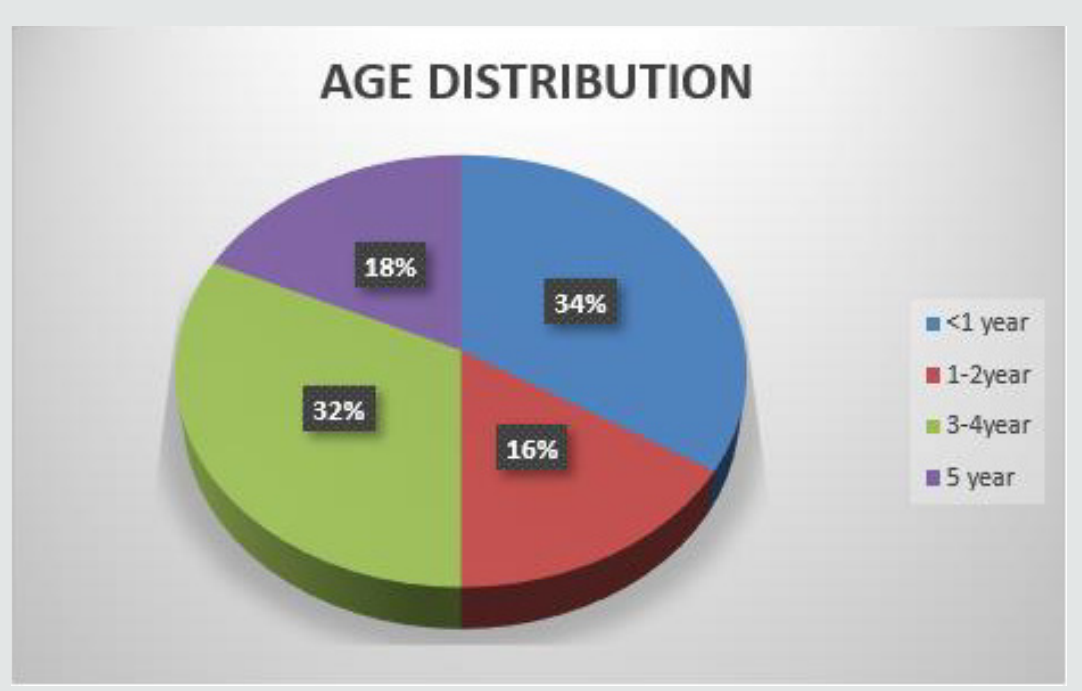

Figure 1: Showing age distribution.

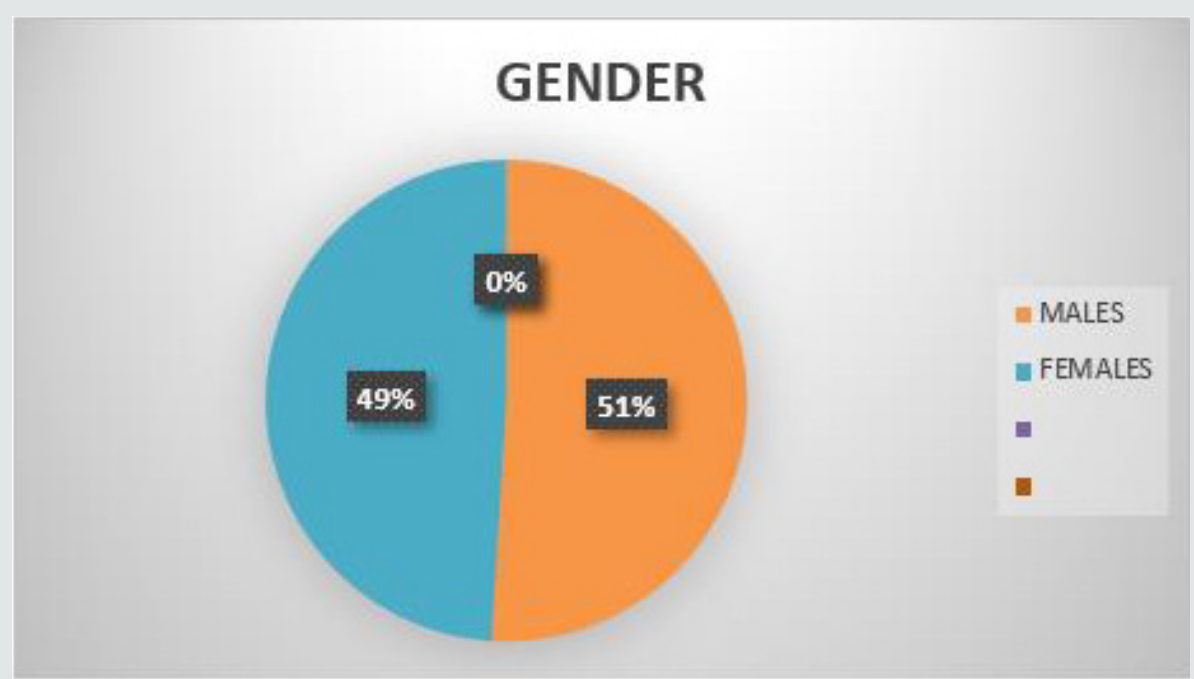

Figure 2: Showing sex distribution.

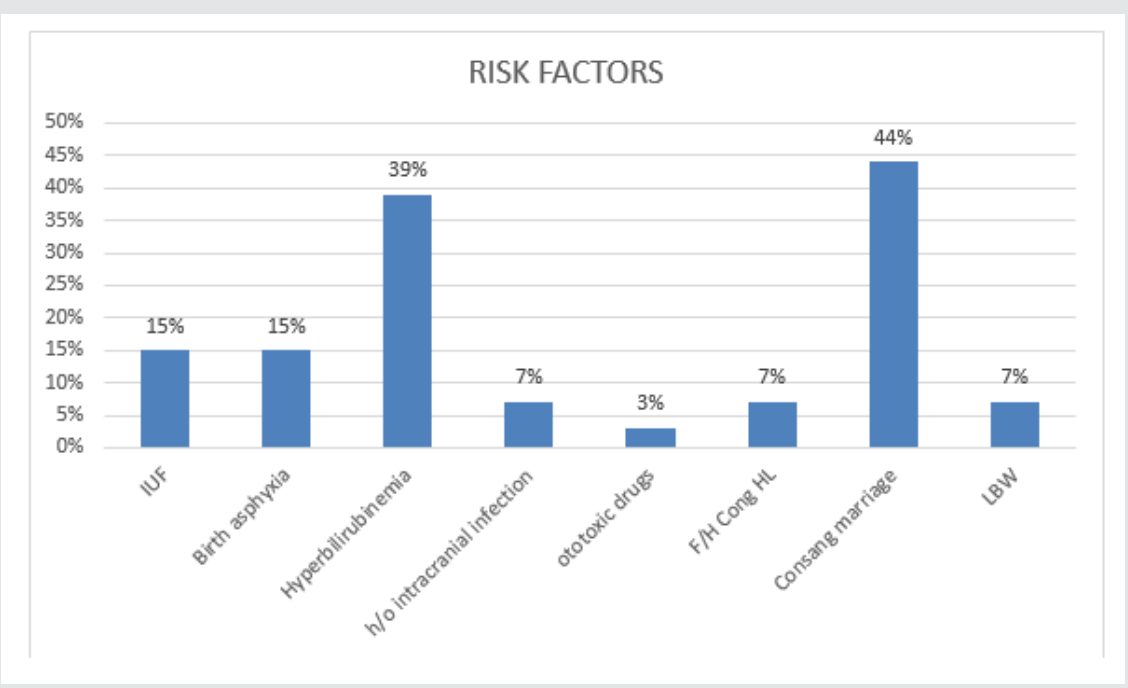

Figure 3: Showing risk factors among subjects. 


\section{Objectives}

a) To find out the incidence of hearing loss in children from high risk category by brainstem evoked response audiometry.

b) To determine the threshold of hearing by brainstem evoked response audiometry in high risk children by observing wave ' $V$ ' at the minimum intensity of click stimulus.

\section{Materials and Methods}

100 children having one or more high-risk factors for hearing loss (up to 5 years of age) according to the inclusion criteria had been selected for the study from the outpatient department of Bangalore Medical College and Research Institute, Bangalore for from August 2019 to July 2020. General physical examination was conducted to know the health status and to rule out any deformities in the subjects. Any local pathology present in ear, nose and throat was treated and BERA was carried out in all children.

\section{Inclusion criteria}

Following high risk children are included in the study
a) History of intrauterine infections (congenital infections)
b) Birth weight $<1.5$ kgs.
c) Hyperbilirubinemia $>20 \mathrm{mg} / \mathrm{dl}$.
d) Moderate to severe birth asphyxia.
e) Maternal or neonatal history of ototoxic drug intake.
f) Documentary evidence of intracranial infections in the past.
g) Family history of childhood hearing impairment.
h) Consanguineous marriage.

\section{Exclusion criteria}

a) Known case of seizure disorders where BERA cannot be interpreted

b) Atresia or stenosis of external ear canal of both ears.

c) Patients not giving consent for BERA.

\section{Parameter studied}

BERA threshold for each ear with absolute latencies of wave I, II, III, IV and V waves interpeak latencies (IPL) of I-III, I-V and III-V and amplitude ratio $\mathrm{V} / \mathrm{I}$ were considered from the recordings of high risk children.

\section{Procedure}

It was performed in dust free, soundproof, air-conditioned room free from electromagnetic disturbances. Syrup Pedichlor (25 mg/kg body wt.) was given to sedate the baby half an hour before procedure. After cleaning forehead, vertex and both mastoid regions with Nuprep (skin prep gel), surface electrodes were placed at the vertex, both mastoids and forehead (ground) and subject was tested in sleeping state with neck slightly flexed to minimize any myogenic activity. Headphone (TDH-39) was held against the ear of baby taking care that external auditory canal does not collapse. $2000 / 4000$ clicks at a rate of $11.1 /$ sec was given and the graphs was recorded on BERA machine Labat Epic- Plus.

\section{Results}

In this study $34 \%$ were in the age group $<1$ year. $51 \%$ were males and $49 \%$ were females. Almost equal number of males and females. In the study $15 \%$ had intrauterine infections, out of 15 subjects, 7 of them had CMV and 8 of them had Rubella. 39\% had Hyperbilirubinemia, $44 \%$ had consanguineous marriage, of them 18 had $2^{\text {nd }}$ degree marriage and 26 had 3rd degree marriage. There was significant difference in mean BERA parameters $(V(d B)$ Threshold, III, V, I-III, I-V, III-V between those with and without hyperbilirubinemia. The above said parameters were significantly high among those with hyperbilirubinemia in right and left ear. There was Significant difference in mean V(dB) Threshold, III, $\mathrm{V}$ and I-V between those with and without H/o Consanguineous Marriage in Right ear. There was significant difference in mean $\mathrm{V}$ (dB) Threshold, $\mathrm{V}$ b/w those with and without H/o Consanguineous Marriage in Left ear. Those with Consanguineous Marriage, majority had mild (35.7\%) hearing loss (Figures 4 \& 5). In this study there was statistically significant difference between wave $\mathrm{V}$ threshold and high-risk factors consanguineous marriage and hyperbilirubinemia. There was no significant difference in mean BERA parameters between those with and without intrauterine infections, low birth weight, intrauterine infections, h/o intracranial infections, h/o ototoxic drug intake, family h/o congenital hearing loss and birth asphyxia in both right and left ear. 26 out 44 children with history of consanguineous marriage had hearing loss out of which 4 were unilateral with mild hearing loss. 34 out of 39 children with hyperbilirubinemia as a risk factor had hearing loss with one child having unilateral hearing loss. 


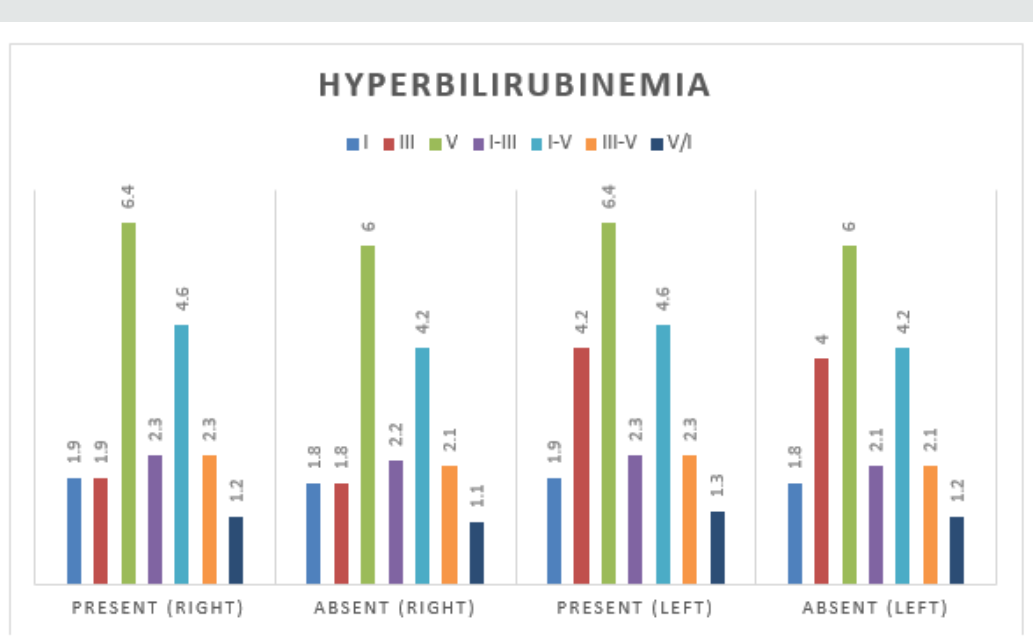

Figure 4: Bar diagram showing Comparison of BERA parameters with respect to presence and absence of hyperbilirubinemia in Right and Left ear.

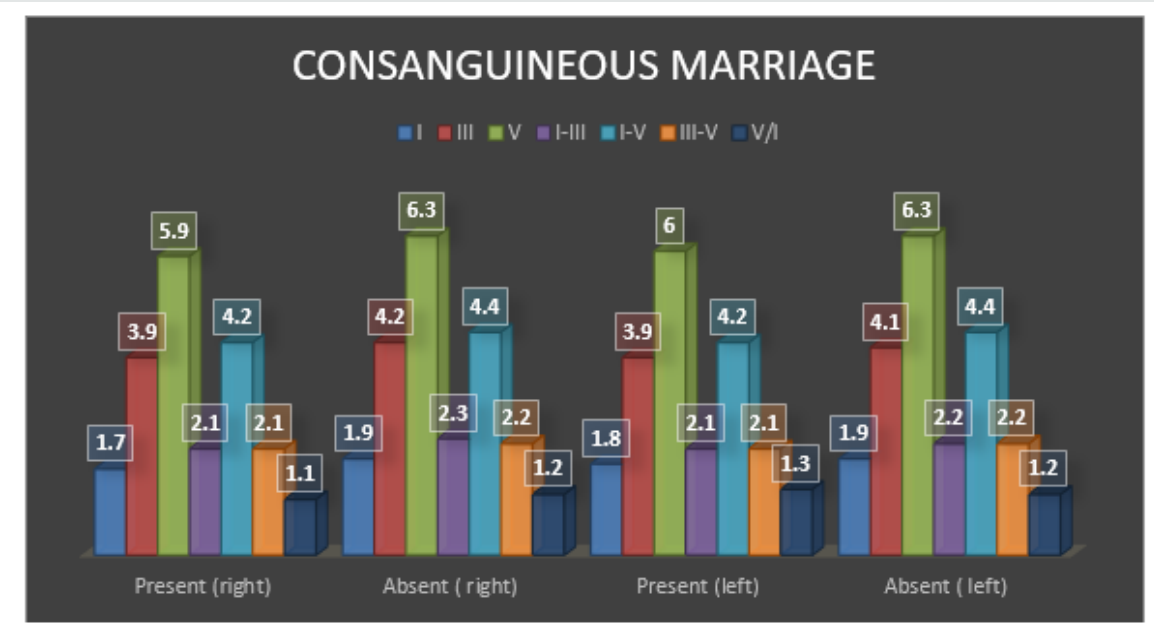

Figure 5: Bar diagram showing Comparison of BERA parameters with respect to presence and absence of consanguineous Marriage in Right and Left ear.

\section{Discussion}

Early detection of hearing loss and intervention is very important for the development of normal speech and language. Majority of children with hearing loss belong to age group 1-5 years between which most of the speech and language development occurs. 4 Interventions usually vary from sign language to cochlear implantation. Brainstem evoked response audiometry although more time-consuming, is an accurate and reliable test for early detection of neural conduction abnormalities in the auditory pathway from the cochlea till the brainstem. The reported sensitivity of the BERA for hearing assessment was 100\% and specificity around 86\% [5]. Earlier perinatal causes like birth asphyxia, hyperbilirubinemia, and intrauterine infections were on the rise but recently inherited causes are on the rise especially in developing countries like India. This is probably due to better treatment facilities and referral centers available. In our study the most common risk factor is shown to be consanguineous marriage showing inherited causes were on the rise. Abnormality at the level of cochlear nucleus and brainstem due to inheritance of abnormal genes. This data is consistent with studies by Ramanathan [4] and Mallikarjun [6] where inherited causes were on the rise. Health education is of prime importance to increase awareness of the detrimental health effects of consanguineous marriage.

The next most common risk factor was found to be hyperbilirubinemia having Wave $\mathrm{V}$ absolute latency was increased in both the ears and also interpeak latency I-V [7]. This indicates that raised bilirubin levels is a important risk factor for detecting hearing loss. 8 In most infants with raised bilirubin levels the values reverted back to normal after treatment indicating that it is a reversible cause and prompt treatment is required. This is similar to a study by Pramod Sharma [7] and by other authors [8-10] in which there was statistically significant correlation in 
prolongation of latency and the interpeak latencies with serum bilirubin levels more than $25 \mathrm{mg} \%$. Follow up of infants with raised bilirubin levels having hearing loss is required. Children with birth asphyxia could have hearing loss due to the depressed end cochlear potential induced by hypoxia and acidosis causing the involvement of cochlea or cochlear nerve showing dysfunction in the peripheral auditory process $[11,12]$. A definitive conclusion cannot be made out regarding the outcome of the study, but it does suggest that all high-risk children will benefit from early detection of hearing loss and rehabilitation through BERA. High risk children should be screened in hospital NICUs, prior to discharge from the hospital and immunization clinics particularly around 6 months of age or below one year using BERA for timely intervention to avoid delay in speech and language development. A national program dedicated to detecting early hearing loss would help reducing the burden of handicap by avoiding delay in intellectual development of the child. Brainstem evoked response audiometry though expensive is a safe and accurate procedure to ascertain whether the hearing loss can benefit through common rehabilitative measures like hearing aids or not. Infants with abnormal BERA recordings should be rescreened within 3 months and several times within the first year. If abnormal responses persist immediate intervention to develop speech and language should be undertaken.

\section{Conclusion}

From our study we can thus conclude that among the high-risk factors, consanguineous marriage seems to be the most common factor causing hearing loss in children. This factor being is a preventable cause, as compared to others, by premarital genetic counseling and health education in lower socioeconomic groups. The next most common factor is shown to be hyperbilirubinemia. This is proven to be a reversible cause of hearing loss according to some studies. Therefore, early detection treatment and follow up is very important in such children. Almost all of the children with a family history of hearing loss had mild to moderate hearing loss suggesting inheritance of abnormal proteins through genes but the sample size for the same was less to derive any significant correlation. BERA was found to be a useful, accurate tool to detect the type of hearing loss and the site of defect in auditory transmission of sound. This aids in planning the mode of intervention for early rehabilitation for speech and language development.

\section{References}

1. Biswas A (2002) Brainstem evoked response audiometry. In: clinical Audio vestibulometry. $3^{\text {rd }}$ Ed, Mumbai, India p. 68 - 88.

2. Ballenger JJ, Snow JB (1996) Diagnostic Audiology and Hearing aids. In: Otorhinolaryngology Head and Neck surgery. $15^{\text {th }}$ Ed. William and Wilkins p. 953-973.

3. Flint PW, Haughey BH, Lund VJ, Niparko JK, Richardson MA, et al. (2015) Electrophysiologic assessment of hearing. In: Cummings Otolaryngology Head and Neck surgery. $6^{\text {th }}$ Ed, Philadelphia, USA Elsevier p. 2071-2082.

4. Thirunavukarasu R, Balasubramaniam G, Kalyanasundaram R, Narendran G, Sridhar S (2015) A study of brainstem evoked response audiometry in high-risk infants and children under 10 years of age. Indian Journal of Otology 21(2): 134.

5. Sharma B, Shrivastava R, Shrivastava A (2016) Brainstem evoked response audiometry in high risk infants. J Evolution Med Dent Sci 5(39): 2463- 2466

6. Patil M, Handi P, Prasenkumar K, Gouripur K (2018) Objective screening of hearing impairment using brainstem evoked response audiometry in children below 5 years of age and assessing the highrisk factors. International Journal of Otorhinolaryngology and Head and Neck Surgery 4(4): 923.

7. Sharma P, Chhangani N, Meena K, Jora R, Sharma N, et al. (2006) Brainstem evoked response audiometry (BAER) in neonates with hyperbilirubinemia. The Indian Journal of Pediatrics 73(5): 413-416.

8. Silva DPC, Martim RHG (2009) Analysis of transient otoacoustic emissions and brinstem evoked auditory potentials in neonates with hyperbilirubinemia. Braz J otorhinolaryngol 75(3): 381-386.

9. Sharma R, Grover N, Shankhyan N, Sharma ML (2006) Auditory brainstem responses in neonatal hyperbilirubinemia and effect of therapy. Indian J otolaryngol Head Neck surgery 58(4): 340-342.

10. Bluestone CD, Stool SE, Alper CM, Arjmand EM, Casselbrant ML, et al. (2003) Ear and Related structures. In: Paediatric otolaryngology, $4^{\text {th }}$ Ed, Saunders, Elsevier p.779-807.

11. Mishra PK, Katiyar CP, Kapoor RK, Shukla R, Malik GK, et al. (1997) Brainstem auditory evoked response in neonates with birth asphyxia. Indian Pediatrics 34: 199-205.

12. Streletz LJ, Graziani LJ, Branca PA, Desai HJ, Travis SF, et al. (1986) Brainstem auditory evoked potentials in full term and preterm newborns with hyperbilirubinemia and hypoxemia. Neuro pediatrics 17(2): 66-71.

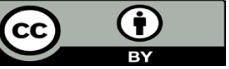

This work is licensed under Creative Commons Attribution 4.0 License

To Submit Your Article Click Here: Submit Article
DOI: $10.32474 /$ SJ0.2020.05.000204

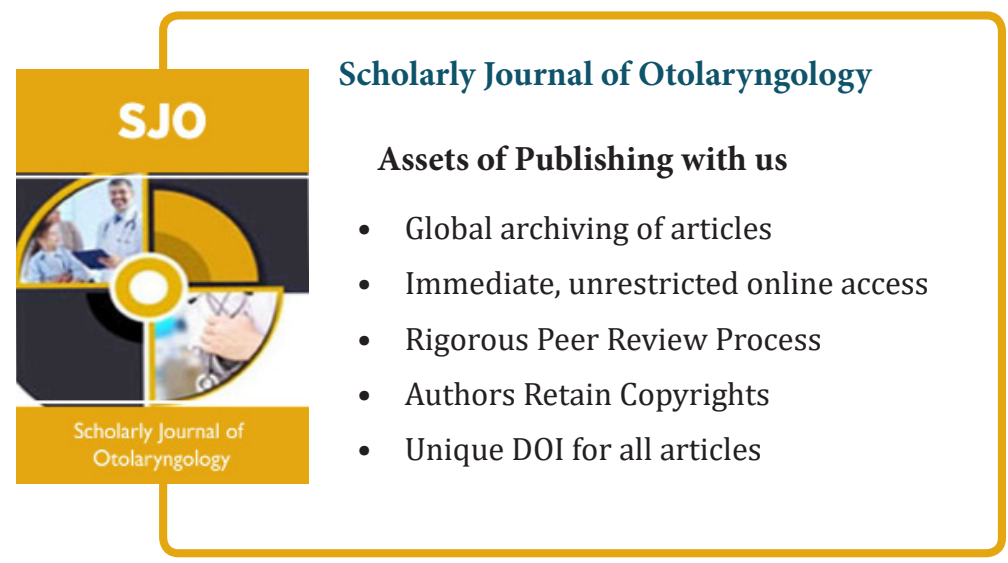

